\title{
Conservative power theory: application in a wind system with DFIG to compensate harmonic currents and unbalance electric current
}

\author{
Ramon R. de Souza ${ }^{1}$, Adson B. Moreira ${ }^{2}$, Tárcio A. S. Barros ${ }^{1}$ and Ernesto Ruppert ${ }^{1}$ \\ ${ }^{1}$ LEPO/DSE/FEEC/UNICAMP \\ Rua João Pandiá Calógeras, 110 Campinas - SP (Brazil) \\ Phone/Fax number:+55 19 35218961, e-mail: ramon.rodrigues11@yahoo.com.br, adsonbmoreira@ gmail.com, \\ tarcioandre@hotmail.com and ruppert@fee.unicamp.br \\ ${ }^{2}$ Federal University of Ceará / Campus de Sobral - UFC, Brazil.
}

\begin{abstract}
This paper presents the application of the conservative power theory (CPT) in the current loop control of the grid side converter (GSC) in a wind energy conversion system (WECS) with doubly fed induction generator (DFIG). The active and reactive power control of DFIG is performed using vector control by orientation of the stator magnetic flux and the analysis of the system is based on simulation results performed in Simulink. The CPT is a technique that allows to decompose the electric current in a given section of the electrical grid in components that represent the behavior of non-linear loads, unbalanced loads and reactive loads connected to the electrical systems. Therefore, the objective of this work is to present the possibility of compensating harmonic currents, unbalances of electric current and to improve the power factor using the CPT in the control of a WECS with DFIG. From the analysis of the obtained results it was observed that adding multiple functionalities to the WECS with DFIG allowing it to operate in order to improve the quality of the electric energy seen by the electric grid. The behavior of the electric current drained by the non-linear and unbalanced load was compensated by the wind system at different points of operation of the DFIG as the results show.
\end{abstract}

\section{Key words}

DFIG, back-to-back converter, wind energy, conservative power theory, active power filter.

\section{Introduction}

The electric power systems are undergoing great changes, particularly as regards the nature of the loads, the proliferation of distributed generation, and the way electricity is being used by consumers. The inclusion of non-linear loads, unbalanced loads and power electronic converters responsible for controlling the energy of distributed generation connected to electrical systems alters significantly the parameters related to the quality of electricity. The power active filters emerge in this scenario as devices that allow the compensation of harmonic, reactive and unbalance currents in order to reduce the disturbances related to the changes of the waveforms of the electric currents that circulate through the electric grid, and consequently of the voltage profile.

Several researchers have studied different topologies of power active filters and different compensation techniques. Although there is no general consensus on which power theory to use for active filtering, important contributions have been made using the instantaneous power theory (PQ) and more recently making use of the conservative power theory (CPT) [1].

Considering that the topologies of the power electronic converters used as power active filters are similar compared with the power electronic converters employed to control wind generators, it becomes feasible to design multifunctional converters, prepared both to adapt the power of the renewable sources to inject in the electrical grid, and to provide the possible support of compensation of harmonic electric currents, unbalanced currents and compensation of power factor when necessary.

Among the various types of electric generators used for conversion of wind energy into electrical energy has the doubly fed induction generator (DFIG) which is widely used in wind farms due to its robustness and versatility in the face of variations in wind speed [2]. The active and reactive power control of these electric generators is usually performed by a three-phase power electronic converter $\mathrm{AC} / \mathrm{DC} / \mathrm{AC}$, where an $\mathrm{AC}$ side is connected to the electric grid using an L or LCL filter, also has a DC bus and the other $\mathrm{AC}$ side is connected to the rotor terminals of the DFIG, according to the illustration of Fig. 1.

Given the intermittent wind regime there are periods in which wind turbines decrease or stop providing mechanical power to the DFIG, characterizing the underutilization of the electronic power converters that perform the active and reactive power control. Therefore, since the back-to-back converter that controls the electric generator is connected to the electric grid, it opens up possibilities of using it to operate as a power active filter. In this work, CPT is applied to measure the load current to obtain the references that are added to the active and reactive power. This technique adding the active filter function to the wind system making it possible to 
compensate for harmonic currents, unbalanced electric currents and allowing to compensate the power factor seen by the electric grid.

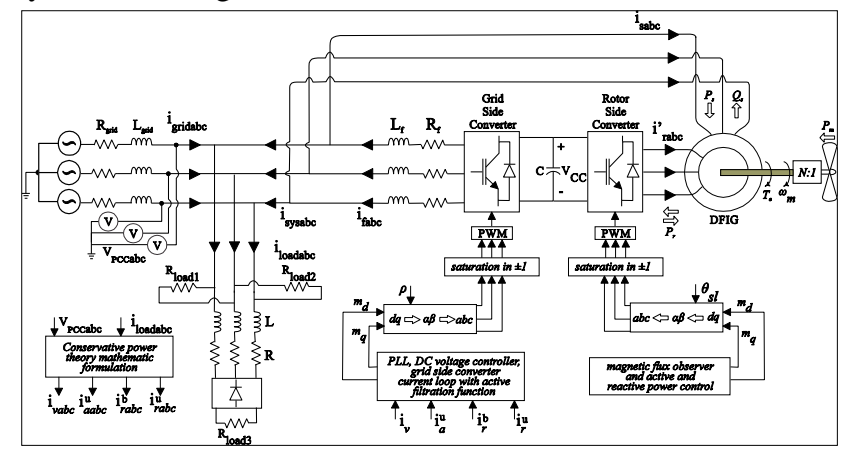

Fig. 1. Illustrative diagram of the studied electrical system

\section{DFIG control}

\section{A. Dynamic mathematical modelling of the DFIG}

The active and reactive power control of DFIG is modeled from the dynamic equations of the electric machine. The equations that determine the dynamic behavior of DFIG in the dq reference frame are presented in (1) to (10) [3].

$$
\begin{gathered}
v_{d s}=\frac{d \psi d s}{d t}-\omega_{e} \psi_{q s}+r_{s} i_{d s} \\
v_{q s}=\frac{d \psi{ }_{q s}}{d t}+\omega_{e} \psi_{d s}+r_{s} i_{q s} \\
v_{d r}^{\prime}=\frac{d \psi^{\prime}{ }_{d r}}{d t}-\left(\omega_{e}-\omega_{r}\right) \psi^{\prime}{ }_{q r}+r^{\prime}{ }_{r} i^{\prime}{ }_{d r} \\
v_{q r}^{\prime}=\frac{d \psi^{\prime}{ }_{q r}}{d t}+\left(\omega_{e}-\omega_{r}\right) \psi^{\prime}{ }_{d r}+r^{\prime}{ }_{r} i^{\prime}{ }_{q r} \\
\psi_{d s}=L_{s} i_{d s}+L_{m} i^{\prime}{ }_{d r} \\
\psi_{q s}=L_{s} i_{q s}+L_{m} i^{\prime}{ }_{q r} \\
\psi^{\prime}{ }_{d r}=L_{r} i^{\prime}{ }_{d r}+L_{m} i_{d s} \\
\psi^{\prime}{ }_{q r}=L_{r} i^{\prime}{ }_{q r}+L_{m} i_{q s} \\
T_{e}=1.5 \frac{p}{2} L_{m}\left(i^{\prime}{ }_{d r} i_{q s}-i^{\prime}{ }_{q r} i_{d s}\right) \\
\omega_{r}={ }_{p} \omega_{m}
\end{gathered}
$$

The mechanical dynamics the wind system is given by

$$
\frac{d \omega_{m}}{d t}=\frac{1}{2 H}\left(T_{m}-T_{e}-F \omega_{m}\right)
$$

In order to perform the active and reactive power control independently, the concept of stator magnetic flux vector orientation is applied

$$
\begin{gathered}
\psi_{d s}=\left|\psi_{s}\right| \\
\psi_{q s}=0
\end{gathered}
$$

The stator electric currents dq components are obtained by substituing (12) and (13) in (5) and (6) resulting in

$$
i_{d s}=\frac{|\psi s|}{L_{s}}-\frac{L_{m}}{L_{s}} i^{\prime} d r
$$

$$
i_{q s}=-\frac{L_{m}}{L_{s}} i^{\prime}{ }_{q r}
$$

The DFIG active and reactive power can be calculated using (16) and (17),

$$
\begin{aligned}
& P_{s}=1.5\left(v_{d s} i_{d s}+v_{q s} i_{q s}\right) \\
& Q_{s}=1.5\left(v_{q s} i_{d s}-v_{d s} i_{q s}\right)
\end{aligned}
$$

Considering that the air gap flux is constant, it can be obtained

$$
\begin{gathered}
v_{d s}=0 \\
v_{q s}=v_{s}=\omega_{e}|\psi s|
\end{gathered}
$$

From (14) to (19) rewrites the active power as a function of the stator current quadrature axis component and the reactive power in terms of the stator current direct axis component

$$
\begin{gathered}
P_{s}=-1.5 \frac{L_{m}}{L_{s}} v_{s} i^{\prime}{ }_{q r} \\
Q_{s}=1.5 \frac{L_{m}}{L_{s}} v_{s}\left(\frac{v_{s}}{\omega_{e} L_{m}}-i^{\prime}{ }^{\prime}{ }^{\prime}\right)
\end{gathered}
$$

Where $v_{d s}, v_{q s}$ represent the stator voltages; $v_{d r}^{\prime}, v^{\prime}{ }_{q r}$ represent the rotor voltage; $r_{s}, r_{r}^{\prime}$ are the stator and rotor resistances per phase; $i_{d s}, i_{q s}$ represent stator dq currents; $i_{d r}^{\prime}, i^{\prime}{ }_{q r}$ represent rotor dq currents; $\psi_{d s}, \psi_{q s}$, represent the $\mathrm{dq}$ components of stator magnetic flux; $\psi^{\prime}{ }_{d r}, \psi^{\prime}{ }_{q r}$ represent the dq components of rotor magnetic flux; $L_{s} \mathrm{e}$ $L_{r}$ are the stator and rotor inductances; $L_{m}$ is the magnetizing inductance; $\omega_{e}$ e $\omega_{r}$ are the synchronous angular electrical speed and rotor angular electrical speed; $T_{e}$ electrical torque e $p$ number of pole pairs.

By using equations (20) and (21) it is possible to control the active and reactive power of DFIG independently.

A back-to-back converter is used in this work, see Fig. 1. It is compound for two converters that have independents control loops.

The RSC (rotor side converter) uses the vector control explained in this section to adjust the active power and the reactive power of the DFIG.

The GSC (grid side converter) is designed to operate on the coordinate system synchronized with the angular frequency of the electrical grid. This converter is connected to the grid through coupling inductors and has dedicated voltage and current control.

In section 3 it is presented a methodology that allows to add the functionalities of compensation of harmonic currents, of unbalanced currents and correction of the power factor of loads in the control loop of the GSC.

\section{CPT application on the GSC}

The conservative power theory (CPT) can be applied in single-phase and poly-phase systems with or without the neutral conductor. The mathematical description is performed in the time domain and concepts described by the authors in [1] are summarized in this section. 
A. Instantaneous active power and instantaneous reactive energy

$$
\begin{gathered}
p(t)=\underline{v}(t) \cdot \underline{i}(t)=\sum_{\mu=1}^{m} v_{\mu}(t) \cdot i_{\mu}(t)=\sum_{\mu=1}^{m} p_{\mu}(t) \\
w_{r}(t)=\underline{\hat{v}}(t) \cdot \underline{i}(t)=\sum_{\mu=1}^{m} \hat{v}_{\mu}(t) \cdot i_{\mu}(t)=\sum_{\mu=1}^{m} w_{r \mu}(t)
\end{gathered}
$$

B. Active power and reactive energy

$$
\begin{gathered}
P=\langle\underline{v}, \underline{i}\rangle=\frac{1}{T} \int_{0}^{T} \underline{v}(t) \cdot \underline{i}(t) d t=\sum_{\mu=1}^{m} P_{\mu} \\
W_{r}=\langle\underline{\hat{v}}, \underline{i}\rangle=\frac{1}{T} \int_{0}^{T} \underline{v}(t) \cdot \underline{i}(t) d t=\sum_{\mu=1}^{m} W_{r \mu}
\end{gathered}
$$

Where $\underline{v}(t)=\left[\begin{array}{lll}v_{a} & v_{b} & v_{c}\end{array}\right]$ and $\underline{i}(t)=\left[\begin{array}{lll}i_{a} & i_{b} & i_{c}\end{array}\right]$ be the voltage and current vectors at a three-phase port. $\hat{v}(t)$ represents the unbiased time integral vector of voltage. The subscript $\mu$ indicates the position of the analyzed quantity in the vector. $p_{\mu}(t)$ and $W_{r \mu}(t)$ represent the instantaneous values of active power and reactive energy, respectively. $P$ and $W_{r}$ corresponding to the collective average values of active power and reactive energy [1].

\section{Current decomposition}

Based on the equations (22) to (25), the phase currents are decomposed into the orthogonal components: active current, reactive current and void current.

$$
\begin{gathered}
i_{a \mu}=\frac{\left\langle v_{\mu}, i_{\mu}\right\rangle}{\left\|v_{\mu}\right\|^{2}} v_{\mu}=\frac{P_{\mu}}{V_{\mu}^{2}} v_{\mu}=G_{\mu} v_{\mu} \\
i_{r \mu}=\frac{\left\langle\hat{v}_{\mu}, i_{\mu}\right\rangle}{\left\|\hat{v}_{\mu}\right\|^{2}} \hat{v}_{\mu}=\frac{W_{r \mu}}{V_{\mu}{ }^{2}} \hat{v}_{\mu}=B_{\mu} v_{\mu} \\
i_{v \mu}=i_{\mu}-i_{a \mu}-i_{r \mu}
\end{gathered}
$$

$\mathrm{G} \mu$ and $\mathrm{B} \mu$ represent the equivalent conductance and reactivity per phase, respectively.

The active current and the reactive current can be decomposed in balanced and unbalanced terms.

$$
\begin{gathered}
i_{a \mu}^{b}=G_{\mu}^{b} v_{\mu} \\
i_{r \mu}^{b}=B_{\mu}^{b} v_{\mu} \\
i_{a \mu}^{u}=\left(G_{\mu}-G_{\mu}^{b}\right) v_{\mu}=i_{a \mu}-i_{a \mu}^{b} \\
i_{r \mu}^{u}=\left(B_{\mu}-B_{\mu}^{b}\right) \hat{v}_{\mu}=i_{r \mu}-i_{r \mu}^{b}
\end{gathered}
$$

All the components defined above are orthogonal to each other. The collective value of the electric current that represents the sum of the rms values of each component and the power factor can be calculated from (33) and (34), respectively.

$$
\begin{gathered}
I=\sqrt{I_{a}^{b^{2}}+I_{r}^{b^{2}}+I_{a}^{u^{2}}+I_{r}^{u^{2}}+I_{v}^{2}} \\
\lambda=\frac{P}{A}=\frac{P}{V I}=\frac{P}{\sqrt{P^{2}+Q^{2}+N^{2}+D^{2}}}
\end{gathered}
$$

$$
\begin{aligned}
& P=V . I_{a}^{b} \\
& Q=V . I_{r}^{b} \\
& N=V . I^{u} \\
& D=V . I_{v}
\end{aligned}
$$

$\mathrm{P}$ is the active power, $\mathrm{A}$ is the apparent power, $\mathrm{Q}$ is the reactive power, $\mathrm{N}$ represents the unbalanced power due the unbalanceds components, $\mathrm{D}$ is the void power that results of void current component.

\section{Compensation strategy}

In order to add the active filtering, unbalanced electric current compensation and power factor correction functions in the DFIG wind system, it was decided to add the calculated load current reference components from (28), (30), (31) and (32).

In Fig. 2 it is shown how the references obtained from the CPT are added to the control of active power and control of reactive power of the GSC. It should be noted that due to the fact that the CPT works with sets of three-phase signals, it was necessary to use the Clarke and Park transformations in case the control is configured to operate in the dq synchronous reference frame.

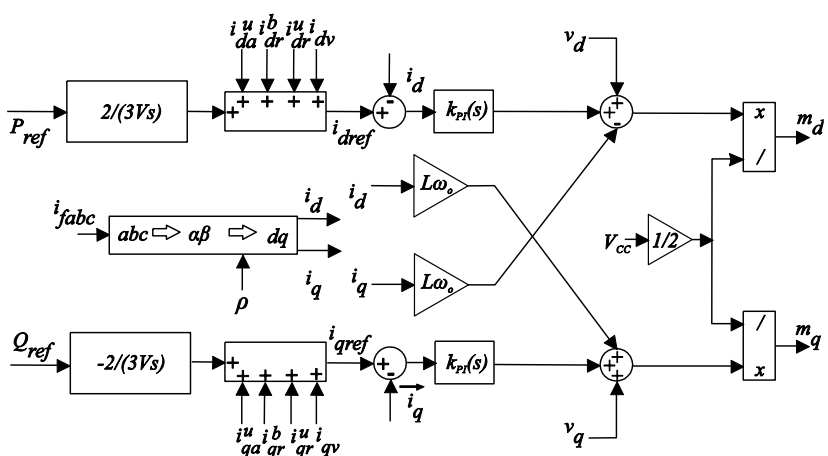

Fig. 2. Control strategy diagram for compensation of harmonic components, unbalanced currents and power factor correction

\section{Simulation results}

In order to validate the compensation strategy for the wind system with DFIG, the schematic diagram of Fig. 1 was simulated in the Simulink extension of Matlab software to observe a case where, over a period of $8 \mathrm{~s}$, the application of CPT was demonstrated for a range of unbalanced and non-linear loads.

\section{A. Decomposition of the load current using CPT}

The voltage at the common coupling point with a peak value of $180 \mathrm{~V}$ for each phase is shown in Fig. 3. 


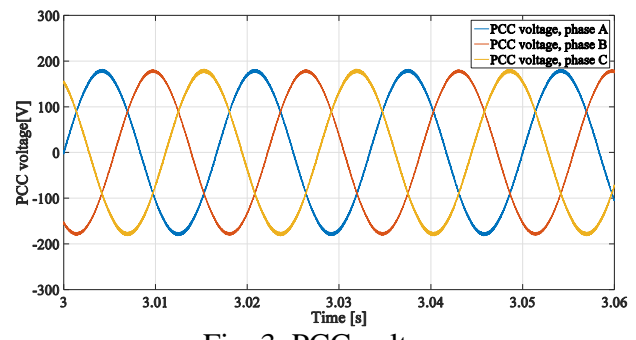

Fig. 3. PCC voltage

The load is composed of an uncontrolled three-phase rectifier and two biphasic resistive loads. The electric currents of the load studied are shown in Fig. 4. As can be observed, the set of electric currents consumed by the load in the three phases presents non-linear and unbalanced behavior.

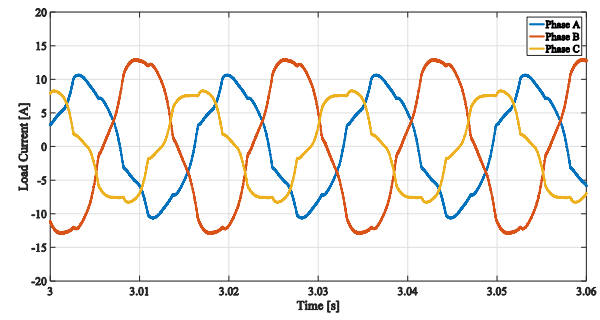

Fig. 4. Load current

Since each phase has a different effective value, THD (Total Harmonic Distortion) is also different in each phase $\mathrm{A}, \mathrm{B}$ and $\mathrm{C}$, as can be analyzed in table 1 .

Table I. - Load Harmonics

\begin{tabular}{|l|c|c|c|}
\hline \multicolumn{1}{|c|}{ Order } & Phase A & Phase B & Phase C \\
\hline $5^{\text {th }}$ & $10.02 \%$ & $7.57 \%$ & $12.05 \%$ \\
\hline $7^{\text {th }}$ & $3.04 \%$ & $2.44 \%$ & $3.92 \%$ \\
\hline $11^{\text {th }}$ & $2.20 \%$ & $1.69 \%$ & $2.67 \%$ \\
\hline $13^{\text {th }}$ & $1.19 \%$ & $0.84 \%$ & $1.38 \%$ \\
\hline THD & $10.95 \%$ & $8.25 \%$ & $13.11 \%$ \\
\hline
\end{tabular}

Using the mathematical formulation of the CPT presented in section 3 an algorithm was developed for the decomposition of the electric current of the load into components that represent the non-linear, unbalanced and reactive behavior of this component from equations (26) to (32). In Fig. 5 shows the unbalanced active current while in Fig. 6 and Fig. 7 show the balanced and unbalanced reactive currents, respectively. In Fig. 8 the void current can be observed.

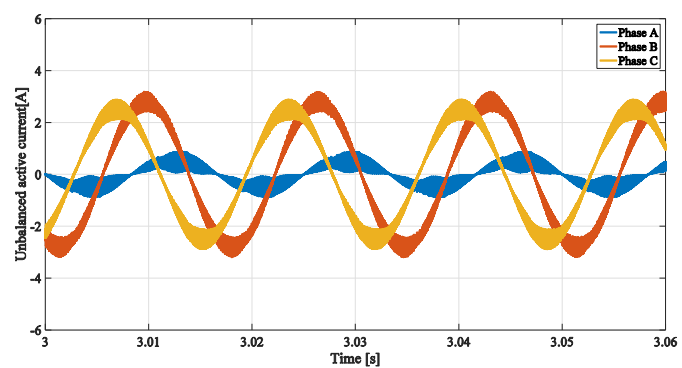

Fig. 5. Unbalacend active current

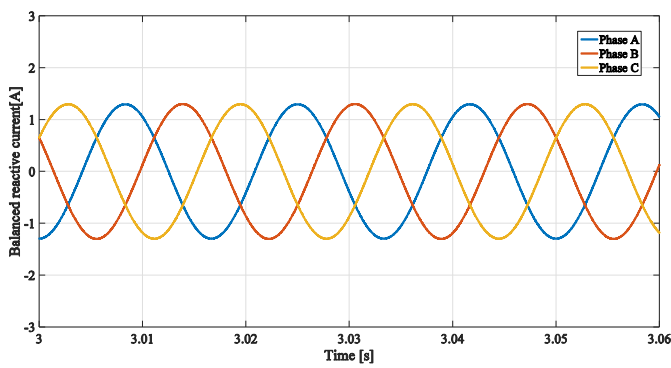

Fig. 6. Balanced reactive current

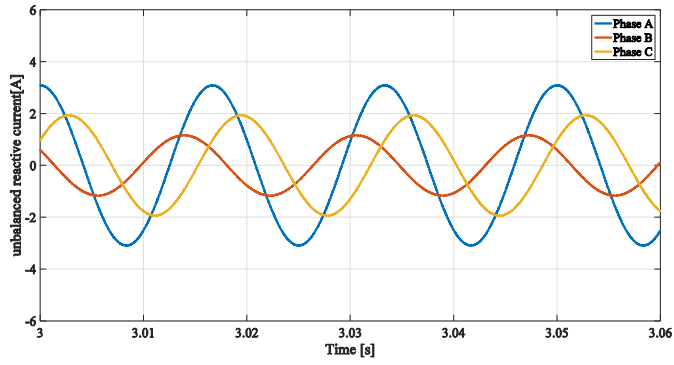

Fig. 7. Unbalanced reactive current

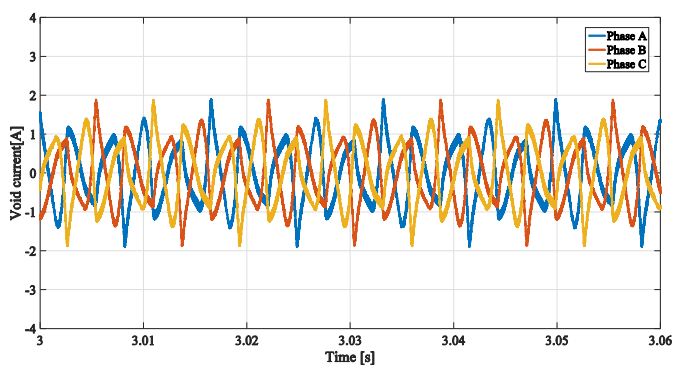

Fig. 8. Void current

\section{B. Description of the wind energy system with $D F I G$}

The studied wind system consists of the wind turbine and a three-phase static back-to-back converter. The DFIG stator terminals are connected directly to the electrical grid. The back-to-back power electronic converter consists of two controlled converters built using IGBT's. A power electronic converter is connected to the electrical grid through an L or LCL interface filter and the other power electronic converter is connected to the DFIG rotor terminals, both of which are cascaded through a direct current bus with capacitors.

The controllers used in this work are of proportionalintegral type and were designed through the frequency response of the L filter, the DC bus capacitor and the DFIG plant.

The grid side converter (GSC) has as main function to control and maintain constant the voltage in the DC bus. In this work we have chosen to add to the control system of the GSC the functionalities of compensation of harmonic components, compensation of unbalanced currents and when necessary to correct power factor. 


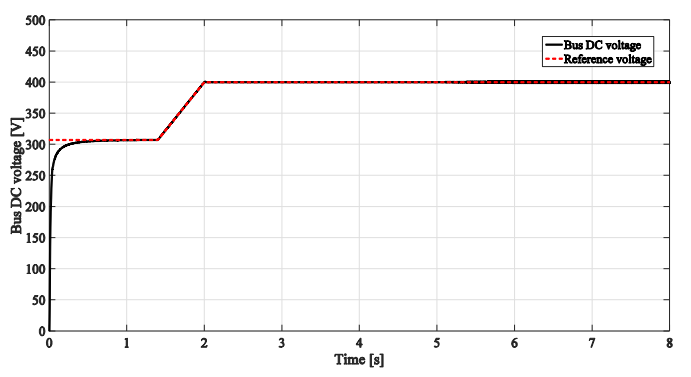

Fig. 9 Bus DC voltage

The function of the rotor side converter (RSC) is to control the active power and the reactive power that flow to the electrical grid through the DFIG stator electromagnetic circuit.

The RSC should be controlled to take advantage of maximum power at different wind speeds depending on the design of the turbine. Fig. 10 shows the speed profile applied to the DFIG axis in this simulation.

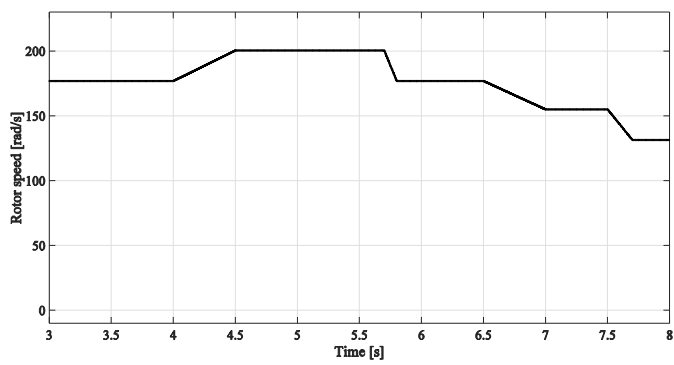

Fig. 10. DFIG Rotor speed

The active and reactive power control is performed indirectly through the equations (20) and (21). The active power injected into the electric grid is shown in Fig. 11, in which it is possible to observe that for each speed value in the generator axis a corresponding active power value is obtained.

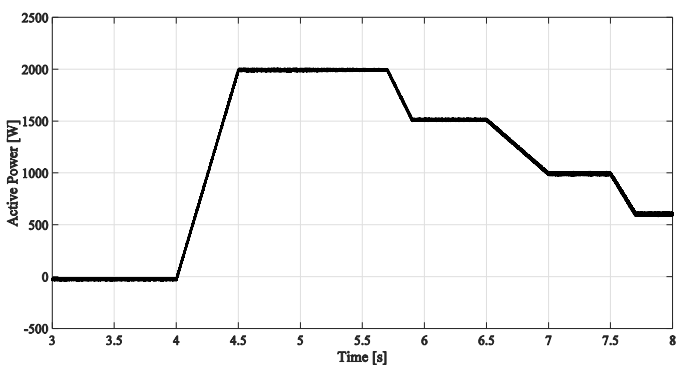

Fig. 11. Active power

As the value of the rotor current direct axis component has been kept at zero for the purposes of this simulation, the DFIG consumes reactive power of the electric grid. Fig. 12 shows the graph with the reactive power profile.

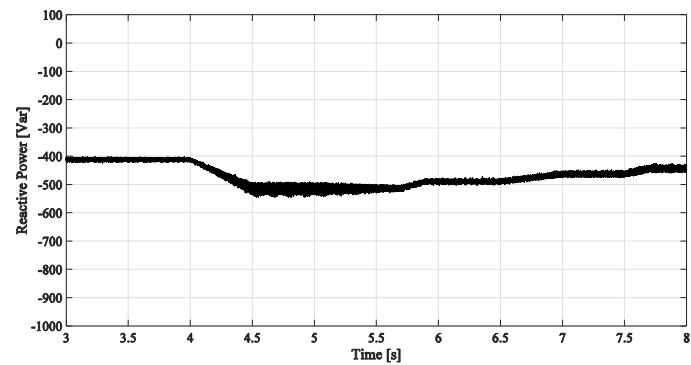

Fig. 12. Reactive power
The electromagnetic torque developed by DFIG is shown in Fig. 13 and its negative value indicates its operation as an electric generator.

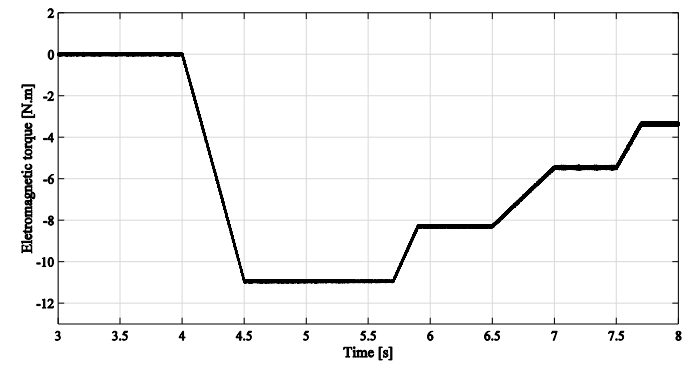

Fig. 13. Eletromagnetic torque

In Fig. 14 shows it the behavior of three-phase electric current in the DFIG stator.

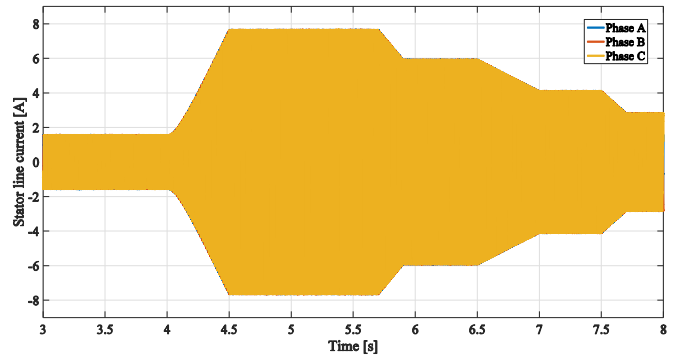

Fig. 14. Stator current

\section{Eletric current on the electric grid}

In Fig. 15 shows it the electric current in the electrical grid before the injection of active power by the DFIG. Note that the instant analyzed in Fig. 15 corresponds to the moment when only the studied non-linear and unbalanced load is connected to the PCC.
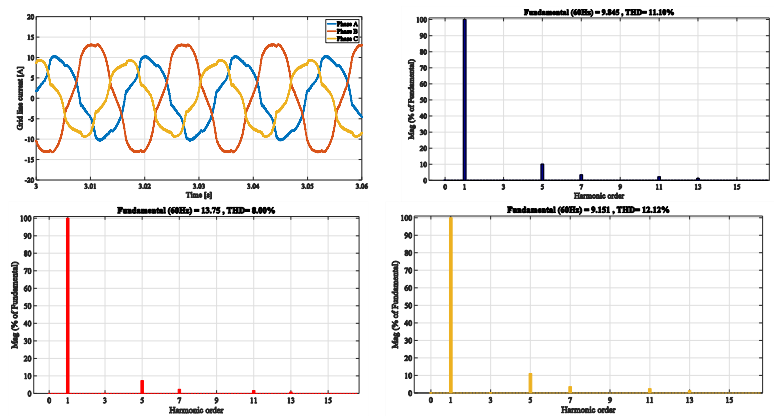

Fig. 15. Electric Current in the electric grid before to inject active power and without active filter function

At time equal to $4 \mathrm{~s}$, the active power DFIG control is activated and the electric current behavior in the electrical grid is presented in Fig.16. Note that the studied load remains connected to the PCC and from $5 \mathrm{~s}$ a part of the energy consumed by it is provided by the wind system. At this moment the active filtering function has not yet been activated and the electric current in the electrical grid has high THD values. 


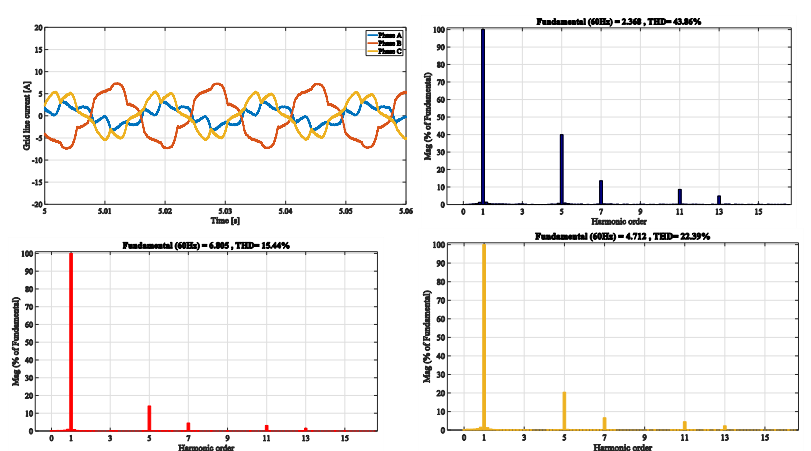

Fig. 16. Electric Current in the electric grid during the first value of active power and without active filter function

In the interval of 6 to 8 seconds the active filtering function using the CPT is enabled and the DFIG wind system continues to inject active power into the grid. In figure 17 it is possible to visualize the result of using the GSC with the function of mitigate harmonic components and compensation of unbalanced currents.

It should be noted that the compensation function of harmonic components and unbalanced components carried out by the GSC provides a greater improvement when the power injected by the wind system decreases. In table II, at $7.7 \mathrm{~s}$ it is noted that the electric currents THD was below $5 \%$ as recommended by the IEEE 519 standard [4].
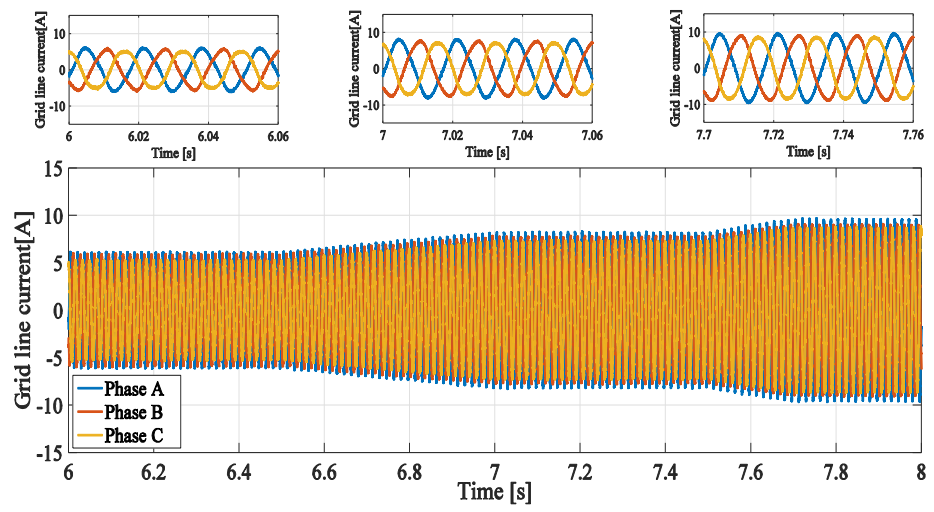

Fig. 17. Electric grid current during the active power injection and with active filter function

Table II. - Grid line currents harmonics

\begin{tabular}{|c|c|c|c|}
\hline $\begin{array}{c}\text { Time } \\
\text { range (s) }\end{array}$ & $\begin{array}{c}\text { Phase A } \\
\text { (Ia/THD) }\end{array}$ & $\begin{array}{c}\text { Phase B } \\
\text { (Ib/THD) }\end{array}$ & $\begin{array}{c}\text { Phase C } \\
\text { (Ic/THD) }\end{array}$ \\
\hline \multirow{2}{*}{6 to 6.06} & $5.68 \mathrm{~A}$ & $5.43 \mathrm{~A}$ & $5.3 \mathrm{~A}$ \\
& $7.01 \%$ & $6.82 \%$ & $7.07 \%$ \\
\hline \multirow{2}{*}{7 to 7.06} & $7.72 \mathrm{~A}$ & $7.43 \mathrm{~A}$ & $7.34 \mathrm{~A}$ \\
& $5.19 \%$ & $4.96 \%$ & $5.1 \%$ \\
\hline \multirow{2}{*}{7.7 to 7.76} & $9.09 \mathrm{~A}$ & $8.79 \mathrm{~A}$ & $8.72 \mathrm{~A}$ \\
& $4.43 \%$ & $4.21 \%$ & $4.3 \%$ \\
\hline
\end{tabular}

\section{Conclusion}

A strategy that adds the active filtering function applying the Conservative Power Theory - CPT in a wind system with DFIG was proposed. For that, the dynamic mathematical modeling of the electric generator, the inductive filter of the GSC with the electric grid and the DC bus were studied. From the dynamic mathematical modeling a frequency response methodology was used to design the gains of the PI controllers of the system control loops. The active filtering function was implemented from the mathematical formulation of the Conservative Power Theory (CPT), which allows to obtain the references that are added to the GSC control and make it possible to compensate the harmonic components present in the non- linear, unbalanced load currents and when necessary to perform power factor correction. As a result, the applicability of the Conservative Power Theory was verified to add multifunctionality to the DFIG wind system through electric current decomposition of the load.

Due to the increase of non-linear loads and the presence of unbalanced loads in the electrical system, it is important that wind power plants be able to offer support, including harmonic current mitigation and unbalanced current compensation. With the application of the active filtering function in the CLR, the THD of the electric current seen by the network at different points of operation of the wind system was reduced.

\section{Acknowledgement}

To CAPES for the financial support for the development of this research.

\section{References}

[1] P. Tenti, H. K. M. Paredes, P. Mattavelli, "Conservative Power Theory, a Framework to Approach Control and Accountability Issues in Smart Microgrids", IEEE Transactions on Power Eletronics, vol. 26, $\mathrm{n}^{\mathrm{o}}$ 3, Mar, 2011.

[2] N. K. Swami Naidu and B. Singh, "Doubly fed induction for energy conversion systems with integrated active filter capabilities", IEEE Transactions on Industrial Informatics, vol. 11, no. 4, pp. 1551-3203, Abril, 2015.

[3] A. Yazdani, R. Iravani, "Voltage-Source Converters in Power Systems - Modeling, Control, and Applications", WILEY IEEE, 2010.

[4] IEEE Recommended Practices and Requirements for Harmonic Control in Electrical Power Systems, IEEE Std. 519-1992, 1993. 